\title{
TEACHER AS A TRANSFORMER OF COGNITIVE AND WISDOM FOR SUSTAINABLE CHARACTER DEVELOPMENT
}

\author{
Hernawati W Retno Wiratih \\ hernawati_life@yahoo.com \\ M Havidz Aima \\ havidz.aima@yahoo.com
}

\begin{abstract}
Development of character virtue is the key to personal, academic, and professional success in life. Today, we face enormous challenges in educating of young people, who provide youth with basic academic, knowledge and skills, accordingly, promote their character development. Modern global culture suffers from a variety of negative trends which are reflected and reinforced in the world of education. These challenges include a perceived decline in the value of intelligence, complex thought, wisdom of superficiality in favor, and the loss of intellectual and moral standards. These conditions will affect their mindset, attitude and behavior that will eventually form of character of individual and community and so will be affected to the society life, especially the characters of young generation. According to Rosenshine and Stevens, 1986, teaching behavior correlate with the student performance to support and develop student's self-identity. Historically, schools have always had responsibility for both academic and character development. Regarding education's wisdom, students need to develop "learning strategies" that support their life-long learning. To do so, education today should facilitate the development of interpretative skills, deep understanding to face and solve the complex problems. Performance of professional teachers must be raised and clearly existence of knowledge by aggregation of skills, technology, and ethics disposition.

Key words: Character, teaching behavior, student performance
\end{abstract}

\section{A. The Nature of Man and Education}

Man, for Wilhelm Leibnitz, the German thinker, was a construct of monads, but differed from the inorganic in that he had a central, controlling monad or soul. Man in all nature, is subject to law, order, uniformity (mechanical universe). Man as a part of the process, he is part of the natural whole and subject to its pre-established laws. Kant undertook the task of restoring man to his dominant place in the universe. He taught that man is a part of the universe as objects and things. In man, Hegel found certain logical processes operating. As man, the universe of which man is a part. As with the human mind, with the universal mind which we find in the mind of man, man is the universe in miniature, man is a little universe which is a miniature of the whole universe.

Society composed of men as an individual and as a whole. Plato and Aristotle develop a taught basically about a man. They said that man was born with natural depravity and was an untrained society help to structure, educate and fulfill his needs. Descartes said, man is two substances of body and soul; and it is impossible to make a satisfactory connection between them. However, we know that the universe was interpreted in term of man, likewise as we have seen, man, is a result of the organization of real. His mental life is fusion, organization of ideas which result from the interaction of real and consequently there are laws which we must obey.

Man differs from animals not only in the possession of human intellegence and purposive will also in the fact that from the time he first appeared in the earth he supplemented his hereditary, physical, and psychic potential with habits, and techniques which increased his comfort, power and safety. Man, therefore, animals, from the ideas he has learned and the material things he has aquired. Talking about human beings and human his existence is always the actual cause and central discussion in a variety of events, because basically man is a creator and problem solver of the conflict and related to survival. According to Descartes (1650-15960) humans are creatures who think (cogito); doubts about its existence the cogito ergo sum is answered. Humans find its existence for thought. Humans are unique creatures, he being a free, autonomous and dependent, he is being a dynamic and multi-dimensional, which is building a relationship with their environment to develop themselves as human beings are basically productive and homo-mensura man into a dimensions that is all to become (what I know; ethical; able to answer; religious).

In the whole course of life, man's development from the primitive and simple to the most complex ways of living, we impressed by the fact that wherever men have lived together there has been some group 
interest in education and as group become more complex this interest grows, and institution in charged with the task of teaching is created. Human beings are uniquely endowed with many abilities. The intellectual and cultural aspects of human life make human beings distinct other animal. Human are capable of learning and being educated. Education ensure survived of the human race, maintain it is intellectual and cultural traditions and helps in developing enlightened.

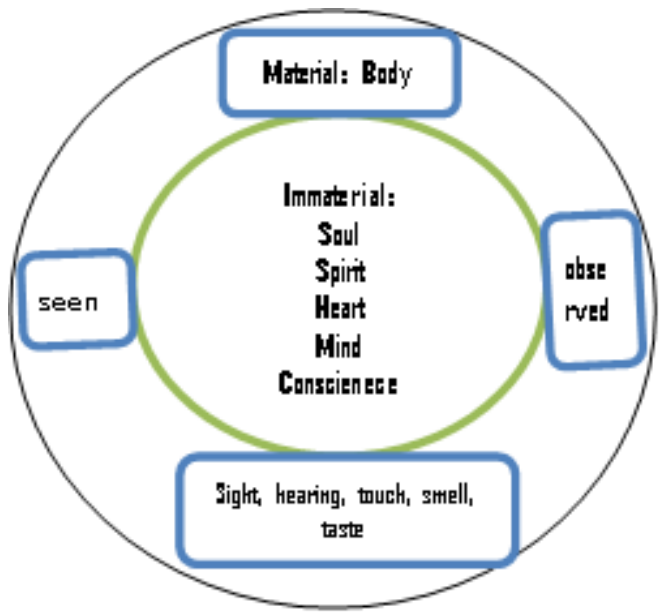

Figure 1: The nature of man and education

Pettit,1993, mention that human being has capacities that allow them to respond appropriately to environmental requirements, but also allow them to care for the appropriateness of their own responses. Human beings are intentional agents that can act on their desires and beliefs, represent their environment internally and find more appropriate means to reach their goals which probably share, come reflexive that call man's educability (Bransen, 2003) that consists in concern for the truth of quality in beliefs and the good quality of one's desires in virtues.

As human beings we are born with a human nature and human dignity that each and every member in the very capacity of being human holds an inherent dignity and worth. Human being is an ideal and a norm, need to be educated and cultivated to develop his or her human nature to become humane. The human being is a rational actor and such creates culture and history, free in many respects and expectations. We may have across the word of 'environment,' even 'environmental education.'

Humans not only learn from the environment (natural, social system, and the economic system), he also learned from the earlier human, processes and developments will shape his pattern of learned behavior and beliefs. Man is reflections human beings who think about the experiences and beliefs that grow out of him. The results of these reflections will be a science when its develop in a critical, rational, methodical, and systematic.

\section{B. The Place of Education in the Development of Individual}

But I will not give them the kiss of complicity.

I will not give them the responsibility for my life. The Leaf and The Cloud by Mary Oliver.

The term education have been derived from educere which means "to draw out" or "to lead out," and it described as a "process of adjusment or developing social process as formation of habits." Our environment has a very great influence on what we are, on what we do and think. Man is greatly influenced by the various of groups life as philosoper John Amos Comenius, a bishop and teacher, believed that it was possible for everyone to learn everything, at first everything should be taught in "general and undefined manner." Besides such external and the social there is a much more important environment which plays upon men, child looks companion, and that is the environment, child develops not only his body but also the mind. These mean, from the earliest childhood a person learns to conform to the thoughts, ideals, habits, sympaties, and tradition of his group. He learns how to feel, to think, to judge as his parents or neighbors do. It teach him self-control, self-reliance, fidelity to ideals and a respect for low. Each child represents a world and aspect of the world and an opportunity to enrich their understanding with a new perspective. In a modern era, varied meaning of education but it has been described as "a process of adjustment" or as a means of "developing social efficiency and remarking of environment" in "developing personality." Its important for child to continue build their core values replacing a negative influences and attitudes with the possitive and role models by 
which the process he will be able to deal with situations and problems positively, as as Rousseau mention that child naturally would follow the natural curiosity of the child and he will learn and grow as trade, then, the child would develop his senses in order to be independent. There are many ways hedging of theoritical issue. Darwin challenged a practice of segregation in which man set himself firmly apart from the animals. The Copernican theory displaced manform his pre-eminent position that center of things. This argument may dissuade people from further inquiry and have any effect. Tolstoy justified that every action of the individual is learning and unique.

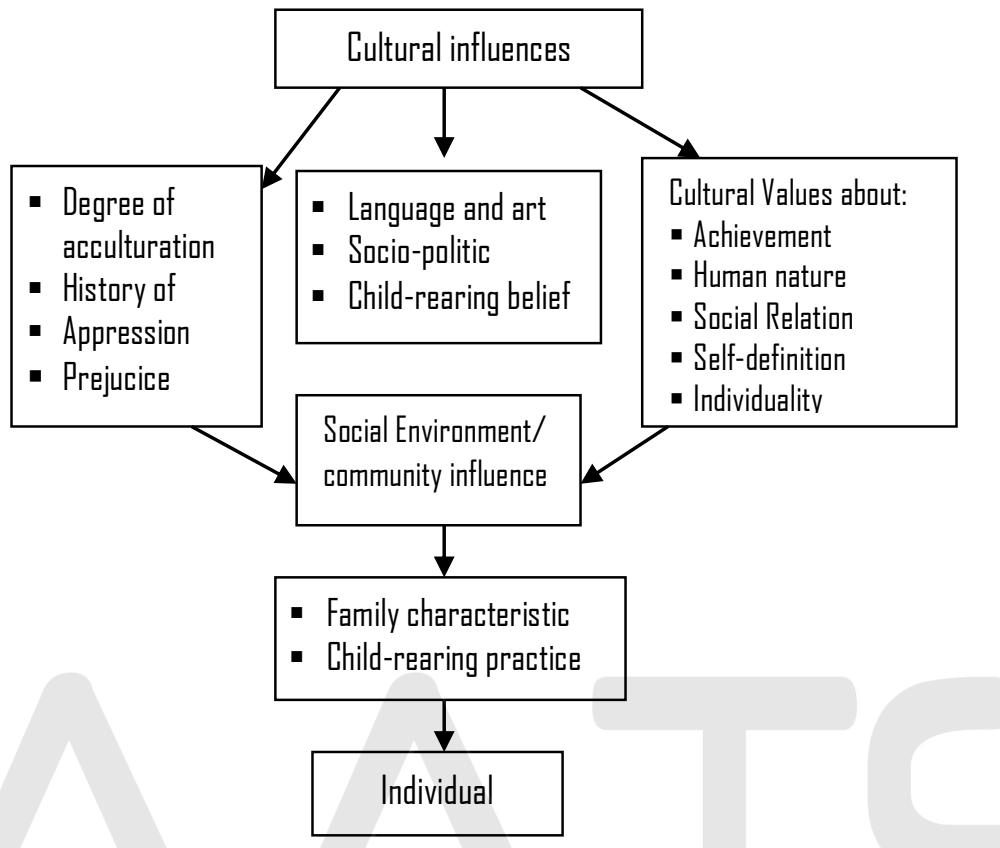

Figure 2: model showing how cultural elements are transmitted to the individual through the medium of social environment and family influences (Source: Psychology, The Science of Mind and Behavioral by Michael WP and Ronald ES, Second Edition)

of child to have greater knowledge and to influenced his conduct. Strictly human conduct which distinguishes in any activity that is specifically human, that is, The social instinct with his desire to express himself to satisfy his ego ever lead him to desire to conform to the standards of those arround him. The provision of good education is an important factor in man's psychic environment, which can counteract to many harmful influences. Develop his intellegence, his ideals, and preferences of the right kind, which will give and develop a deeper understanding performed with rational insight and controlled by will, behind that is mental state. The constant mutual interaction of the individual and is environment which is human conduct in a complex thing, and its outomathic, that is his actions are habitual which gained from environment who changed by the working of mind and imagination. Education designated as a process of viewing and recording behavior as occurs in natural situations to help child build and organize their character in individual and group setting, to provide a greater functioning and facility as well as greater complexity to lead his body and mind toward his maturity.

\section{Education, the Necessity and Function}

The major activities of school are learning and teaching. Other activities, including administration, curriculum construction, guidance, and methodology, likewise play important roles in the process of modern education. The purpose is fundamentally and primarily to facilitate and to render more effective the major activities of learning and teaching. Both of these major activities are by their nature complex and in the school situation are necessarily coordinated. Both are essentially mental processes. Learning is the mental activity by which knowledge and skills, habits and attitudes, virtues and ideals are acquired, utilized, retained, and resulting in the progressive adaption and modification of conduct and behavior. Both are essentially mental processes. To provide the necessary motivation and direction, effective guidance and control and likewise to evaluate learning activity the teacher must have an understanding of the basic laws and principles which govern the development of the growing pupils. 
Education is a science while teaching is an art. The art teaching is about creativity which depedent on knowledge of effective techniques and also upon the application of these techniques. Education is the culture of mind, the will and the emotions adapting a man for the exercise of the harmonious development of their powers, capacities, capabilities (moral, mental, spiritual, physical, social life, and emotional). Education depend premarily on the nature of the one to be educated. Human beings are composed body and soul, hence, to educate a child means the development, naturally and harmoniously, all of powers and capabilities of body and soul.

Education oriented needs of students based on his skills and knowledge, to increase his motivation to learn and increase material needs of students. The theory is applied to students who are assumed to be adapted to the characteristics derived from the student's motivation is built of intelligence culture behavior that includes mental and emotional characteristics of student's and talent or intelligence and aptitude of students. It is modified or developed that will influence to learning outcomes. The success of this depends on the interaction of student such environmental, mental and aptitude. In education, people who think systematically designed pupils are able to understand and live with also able to communicate with. Hence, educational must consider to the whole being of man. It cannot consider the child as other being endowed not only with and sense, also with soul and intellect, and will. In the time, how ever, as traditions and customs grew, this simple association together is not enough. The child could not learn all that was necessary, and the old men of the group took it upon themselves to instruct the young at certain times in tradition and customs. As the life of group become complex, certain members of the group took it become thoroughly familiar with the tradition and education and devoted most of their time to the teaching. Teaching and learning was due to the fact that among them ways of living and tied up each other, worship, compliance to be the power who established a traditions where united in education.

Human are neither the strongest nor the biggest even the fastest of all creatures, specifically to their environment. Obviously, their intellectual abilities and socio-cultural aspects more than compensated for what they lacked. Locked in permanent struggle against environmental condition. By co-existing in the form of families, he acquired knowledge and experience and learn how to know and express, and so, this is the begining of education. Education have crucial role of intellectual and social-cultural tradition of human life, and since human life get training of intelectual and cultural aspects to become effective member of his group. Education for human is necessaty of life. The necessaty of education much greater in modern era. The human child needed to learn much less concentrating on vital material task to lead an effective life. With the accumulated experience, consecuently, the need for better education for learning become effective. This potentialities need a favorable environment and care for their flowering. Education is empowering human to lead a succesful life and makes them fit for their environment. Education of an individual is always directed to the possible growth of human abilities for 'harmoniously personality.' The process of education provides stimulation and the care necessary for actualisation of potensialities, responsibility, and balance of developing abilities.

Education is productive energies in society such a regular supply trained of skilled of man power as human resource. Its develop individuals intellectual and enabling them to review the structure and functions of society, and so, education has an influence on the environmental condition to perform a certain functions.

\section{The Basic Teaching as a Transformer for Wisdom and Character Sustainability}

Among the Greeks as we have seen, they believed that man should be trained to take care of himself and advance himself in his community. Their gods were believed to be the power who establised traditions. Traditions were closely to the education that everything was learned from the oldest and teachers that places of learning should be in intimacy, and will advocated them which promote the succes and happiness of the individual.

The meaning and understsanding of wisdom has changed. Brugman (2000) describes this transition succinctly, "troughhout history the meaning and understanding of wisdom gradually change, took place in which wisdom coincided with roles for proper conduct with virtue and faith as advocate." The concept of wisdom as a human attribute has changes. Contemporary science, wisdom has come to be regarded as a trait that is ascribed to persons of making wise decisions, or having an effective decision-making style. In this sense, wisdom is a very broad trait of the highest level of mental functioning. Wisdom requires that an individual must have experience, seek information, and weigh alternative outcomes of a decision through complex or dialectical reasoning.

Birren and Fisher (1990) in their review, attempted to integrate the definition as: "Wisdom is the organismic integration of the affective, conative, and cognitive aspects of human abilities in response to life's tasks and 
problems. Wisdom is a balance between the opposing valences of intense emotion and detachment, action and inaction, and knowledge and doubts." In a broad view, psychology appears to be on the treshold of dealing with the subject of wisdom which perhaps represents the highest order of human ability. It is likely that will identify the nature of wisdom and the circumtances leading to its development and expression, a quality that the ancients thought was solely found in gods and goddesses.

In the West, the concept of wisdom express as a sort of pragmatic tool to "make sense." Wisdom referred to a set of socially accepted moral and religious codes, practical virtues like patience, honesty, and conformity, while denouncing antisocial vice such as greed and selfishness (Bryce,1979; Wood, 1967). Some investigators claimed that the moral and religious codes potrayed in this ancient text was similar to those found in other ancient civilizations of different regions such as Africa, China, Mesopotamia (Assmann, 1994). This tradition was incoporated into more organized as the Hebraic wisdom (Crenshaw, 1976). In addition to cultivating one's cognitive ability through formal education and parental guidance, the Hebraic tradition also emphasized a strict adherence to religious faith as an ultimate path to wisdom (Assmann, 1994). The book of Job, a story about a man's struggle to find meaning amid a series of misfortunes. In this story, wisdom entails one's recognition of his/her place in a Divine Order that is far beyond human cognitive capacity, and only the highest adherence to faith is believed to lead to this recognation ( $R a d, 1972)$.

Eastern wisdom refers to a process of direct understanding without overt intellectualization, and with a great deal of emotional involvement. When a situation requeres an intense, emotion, understanding, formal and cognitive oriented to imply more direct and get feeling understanding. This refers to cognitive as well as emotional exerience of mutual understanding. It is important to understand, Eastern teachings often deemphasize intellectual learning toward transformational and integrative wisdom, so called, personal striving through a cultivation of one's moral, intellectual, emotional commitment to learning. Eastern tradition equally embraces. The pragmatic and cognitive components of wisdom along with the transformational and integrative. For example, an acumulated domestic knowledge is referred to as "a sack of grandma's wisdom" and is treasured by family members for its practical utility.

As Eastern, however beautiful some places may be to the eye, some have quality that is depressing, forlorn, and empty. Often overlooked in the West is the "feel of a place," a quality of vibration of harmonious with the activity to take place there. Lindsey, her comments on the area of Loch Tay convey a strong feeling of an enchanted "place." She wrote," extraordinary things keep happening all the time in a most synchronistic and serendipitous way." Here, strong feeling that "place" itself want to be developed to become a center of culture and wisdom.

The Javanese have a long recognized this concepts as "rasa" (both good and bad), a vibration or quality which may emanate from diverse sources and imbue the "place" with a potential for good or ill. For this, we have known in the West also, at least in small ways, but seldom utilize it, putting economics, or social considerations ahead of the "spirit" of place. Here the following example of what the Javanese call "rasa": a) about equality of humanity: "wiwit cilik bocah wus diparingi pangreten menawi sedhoyo manungsa puniko sami, ingkang mekaten supadhos tansah asih tresno marang sesame" - from early age children have been taught with understanding that man are equal, therefore we should sharing love; b) about living in truth: "linambaran pengati-ati anggenipun bebrayan nindakaken dharmaning gesang, tinuntun lampahing dhumateng margi ingkang leres lan bhecik, leres ateges mboten klentu, dene bhecik ateges pantes dados tepo tuladha - by carefulness (awareness), we live among others for the essence of life, our steps are guided within the passage of truth (not being wrong), and goodness.

The different conceptualization of wisdom between Western and Eastern found that it is of interest to know how these traditional meanings may have had an impact on the understanding of wisdom across cultures. In a large scale study, Takayama (2002) examined the implicit theories of wisdom among Japanese men and women about behavioral attributes, and found that there are four distinctive factors: knowledge, and education, understanding and judgment, sociability and interpersonal relationship, and introspective attitude. Takayama conclude that Japanese are more likely to define wisdom as a "practical" and "experience-base" competence but less likely to associate with reasoning ability and general intelligence. Similar study Taiwanese Chinese, Yang (2001) also found four comparable factors: competencies and knowledge, 
benevolence and compassion, openness and profundity, and modesty and unobtrusiveness. These result suggested that Taiwanese Chinese defined wisdom in less spiritual and less religious fashion, but more pragmatic concept expressed in daily life that brings "harmony" to a society as a whole. This is characteristic relatively unique to Chinese-origin cultures.

With the aim of implicit theories of wisdom, include the identity common factors, wisdom-related descriptors (Holliday\&Chandler, 1986; Takayama, 2002; Yang, 2001) and their relationships (Clayton\&Birren, 1980), make a comparisons of wisdom with intelligence and creativity (Stenberg, 1986), and describe the characteristics of wise people or those actual people who have been nominated as wise. Several definitions of wisdom-related concepts such as intelligence and spirituality have been cross-culturally (Nisbett, 2003; Takashi\&Ide, 2003), that to generalize the implicit theories of wisdom beyond the conventional European American. Valdez (1994) interviewed by 15 Hispanics Americans, and she found that their definitions of wisdom stressed the spiritual and interpersonal dimensions. Each of these studies presents additional evidence to the common-sense variability of the meaning of the wisdom and demonstrates specific ways that wisdom has been conceptualized across cultures.

\section{E. A Sustainable Character Development}

What kind of world should we build for our children to inherit?. Beyond the hearth, child rearing has always ambiguities and the issues for today's parents are how to raise decent kids in a complex and morally ambiguous world where school and neighborhood are badly frayed. "Education" is in no way limited to classrooms but is a mission that must be undertaken and realized by human society as a whole. We must now go back to the original purpose of education - children's lifelong happiness - and reflect upon the state of our respective societies and our ways of living. At the threshold of a new century, we have a great opportunity to seriously face these issues - and it is an opportunity we must seize. Instead of the powerless deriving from despair, helplessness, defeatism, self-doubt, pessimism, indifference, cynicism, and apathy, we need to engage in vital, volitional, proactive, and energetic efforts-in Spinoza's words, "virtue that springs from force of character."

Thoughts on culture, wisdom, and education is the creation of a human society that serves the essential needs to emphasize the global challenge of character of human beings that faces us. Cultural battles rarely reflect the complexity of human behavior, and proper moral child rearing like a black or white quality. "Moral education involves explicit instruction, exhortation, and training. Moral education must provide training in good habits," with such preoccupation drill "human potential" construct a habit, moral and empathy (Bernett, 2003). Psychology of learning found the relevance for understanding personality. Many behaviors ascribed to personality are acquired through classical conditioning, operant conditioning, and model conditioning (Bandura, 1999). However, the leaner is not simply a passive reactor to environmental forces, as though the cognitive perspective says that the human is a perceiver, a thinker, and a planner, who mentally interprets events, thinks about the past and anticipates the future, and decide how to behave. Environmental effects are filtered through these cognitive processes and are influenced. A key factor in how people regulate their lives is their sense of self-efficacy, their beliefs concerning their ability to perform and their desired outcomes.

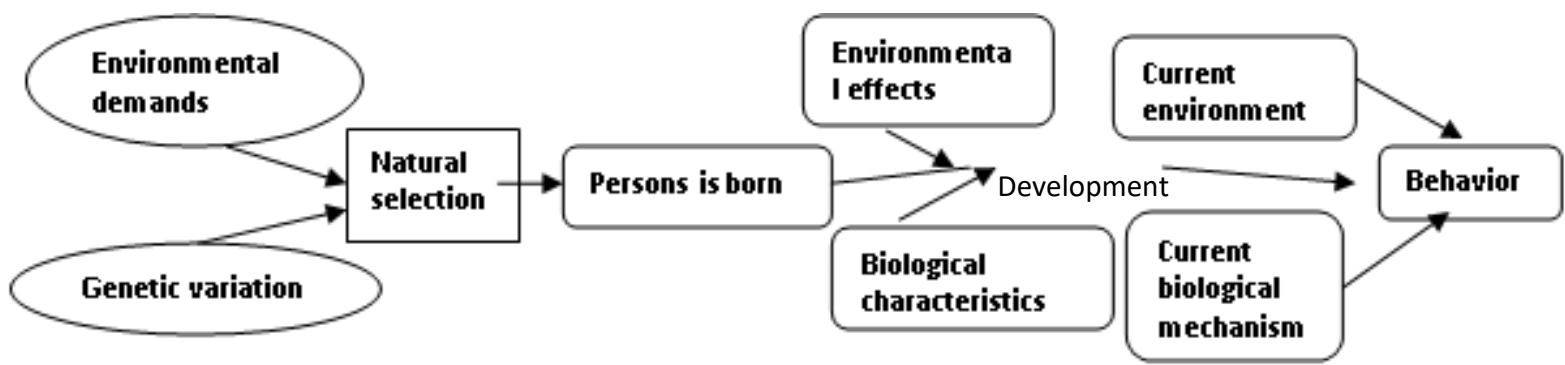

Figure 3: Biological and environmental factors interact and influence one another by interaction of nature and nurture.

Cultures differ along a number of dimensions that can affect personality development (Triandis \& Suh, 2002), a) is complexity, how much more complex or potential (information or gather) culture for diversity 
and conflict of values and behavioral norms exists; b) culture's tightness there are many rules about behavior, and those who deviate from the cultural norms, even in minor ways. For example, in Singapore, adolescents are expected to adhere strictly to social norms that forbid experimenting with alcohol and tobacco. Important personality differences have found between people in collectivistic who see the environment as fixed (having rigid roles and expectations), and in contrast individualistic cultures are more likely to see themselves and their personalities as relatively stable and the environment as malleable, so that if they don't like their situation, they can leave it or change it (Hong, 2001). Self-enhancement need equally strong in individualistic and collectivistic cultures, but they are satisfied in different ways.

In development approach, cultural wisdom is embedded in theoretical framework for the study of intellectual development that interacting categories of intellectual functioning that is mechanics and the pragmatics of intelligence (Baltes, 1987). The cognitive mechanics refer to the neurophysiologic architecture of the brain as it has evolved during biological evolution. The cognitive pragmatic are thought to show stability indicated by culturally transmitted bodies of knowledge. The importance of experience in acquiring knowledge-based skills showed by typical activities are reading and writing skills, educational qualifications, or skills related to practical problems of everyday life.

Typical of wisdom are the bodies of knowledge, however go beyond those subsumed under other more limited forms of pragmatics intelligence and represents prototypical of the cognitive pragmatics. In fact, wisdom as expert knowledge about fundamental life problems is meant to expand the traditional that close to intellectual functioning, because component of cognitive pragmatics requires a return to the original conception of intelligence as general adaptation to the changing biological and environmental conditions inevitably taking place throughout the lifespan. Notion that intelligence and intelligent behavior need to serve a broader purpose than academic achievement is an important motivating factor to develop. High value and outstanding expertise that dealing with fundamental, that is existential, problems related to the meaning and conduct of life (Baltes and Smith, 1990). The problem typically complex and poorly defined. Deciding on particular path, accepting death of a loved one, dealing with personal mortality, or conflicts among family members exemplify the type of problem that calls for cultural wisdom.

Expert knowledge about meaning and conduct of life is thought to approach cultural wisdom to meet all five criteria labeled, these are: a) rich factual knowledge about human nature and the life course; b) rich procedural knowledge about ways of dealing with life problems; c) lifespan an awareness and understanding of many contexts of life (how they relate each other and change over the lifespan; d) value and tolerance, that is, an acknowledgment of individual, social, and cultural differences in values and life priorities; e) knowledge about handling uncertainty, including limits of one's own knowledge (Baltes\&Staudinger, 2000). Cultural wisdom is related to performance is assessed by presenting individuals with fictitious life dilemmas. The abilities deal with uncertainty, inconsistency, imperfection, and compromise. Pivotal for post formal thinking is the transcendence of universal truth criterion formal logic, a tolerance of ambiguity created by an acceptance of multiple truths. However, the relationship stages of development post formal with an area at least related to personality domains, that is, social cognation. It was also found that positive mood induction and relaxation improved post formal whereas focusing attention had detrimental effects (Sinnott, 1991). In sum, we may conclude with regard to the personality-wisdom relation that "wise thinking" sense is related to tolerant and open-minded attitude, which is also characteristic of personality dimensions, that is "openness to experience." It seems easier to think "wisely" when one is relaxed and in a positive mood.

In Sternberg's (1998) approach wisdom is related both practical and academic intelligence. Academic intelligence provides a necessary but by no means sufficient basis to wisdom-related functioning. Wisdom also involves the application of tacit knowledge (Polanyi, 1976), which is the key aspect of practical intelligence. Tacit knowledge is action-oriented (procedural) knowledge that is usually acquired without direct help from others and that allows individuals to achieve goals that they personally value.

Commonly mentioned, cultural wisdom related to character that similar to the recognition of uncertainty, involves the recognition that different point of view, such as considerations of values and contextual of lifespan, or otherwise integrate awareness. Persons first recognize a diversity of viewpoints in searching for solution and then develop a holistic self which symbolizes wholeness and completion or systemic and 
awareness, these occurs within numerous cultures and religions. This component reflected a balance among intrapersonal, interpersonal, and extra personal interests.

Cross-cultural differences can exist however, even when cultural equivalence is found within the structure, Triandis and Suh (2002) averred that personality may reflect both universal and culturally specific aspects of personality. To support this, some studies suggest that the personality dimensions express themselves differently in different contexts. Yang (1986), found that Chinese (samples score) lower than relative to American samples on the dimension of extraversion. Similarly, McCrae, Yik, Trapnell, Bond, and Paulus (1998) found that Chinese Canadians scored lower than their Europian Canadian on Extraversion, lower on Openness, and higher on Neuroticism and Agreeableness. Also, Mastor, Jin, and Cooper (2000), found that Malays scored higher relative to Western samples in Agreeableness and lower in Extraversion and Openness. These group differences suggest that cultural context may be associated with personality.

One factor that connects cultural context and personality is cultural values. Cheung et.al.'s (2001) work on Chinese Personality Inventory includes the dimension of interpersonal relatedness, a value that is highly emphasized in many East Asian cultures. In addition, the value of collectivism and individualism, for example, may play a role on how personality is perceived and expressed (Williams, Satterwhite. \& Saiz, 1998). Furthermore, Konstabel, Realo, and Kallasmaa (2002) found that cultural groups scoring high on collectivism scored lower in extraversion and agreeableness compared to normative American sample. That is because Asian cultures tend to be high on collectivism, their personality expressions may be more highly associated by social context. In a culture that emphasizes interdependence and in-group norms, Agreeableness may facilitate the maintenance of social harmony while extraversion may violate those values.

\section{F. PERSONAL WISDOM AND THE MATURE OF SELF}

The concept of personal wisdom is integrating in the definition of wisdom with conception of personality growth with regard to the characteristics of a mature person in the areas of cognition, emotion, motivation, and volition. This criterion is rich self-knowledge. A self-wise person, will be aware to his or her competencies, emotions and goals, and have sense of meaning in life. Self-wise person have an available heuristic (humor) for growth and self regulation, that how to express and regulate emotions or how to develop and maintain deep social relationship. Humor is important to help person to cope various difficult and challenging situations. Interrelating the-self, that is refers to the ability to reflect on and have insight in the possible causes of one's behavior and/or feelings. This implies there is awareness about one's own dependency on others; they show for others' value and lifestyles.

The coping of self-efficacy-the belief that we can perform the behaviors necessary to cope successfully-is an important protective factor (Bandura,1989). The "three Cs" of term hardiness are commitment, control, and challenge. Such though a complex perception, disappointed or pain is influenced by numerous factors. Hardy people are committed to their work, their families, and their other involvements, and they believe that what they are doing is important. Finally, they appraise the demands of the situations as challenges or opportunities, rather than as threats. Cultural learning, meanings attribute to pain, beliefs, and personality factors all affects of experiences of pain. The interpretation of pain impulses sent to the brain depends in part on our experiences and beliefs, and both of these factors are influenced by culture in which we develop (Rollman, 1998). 


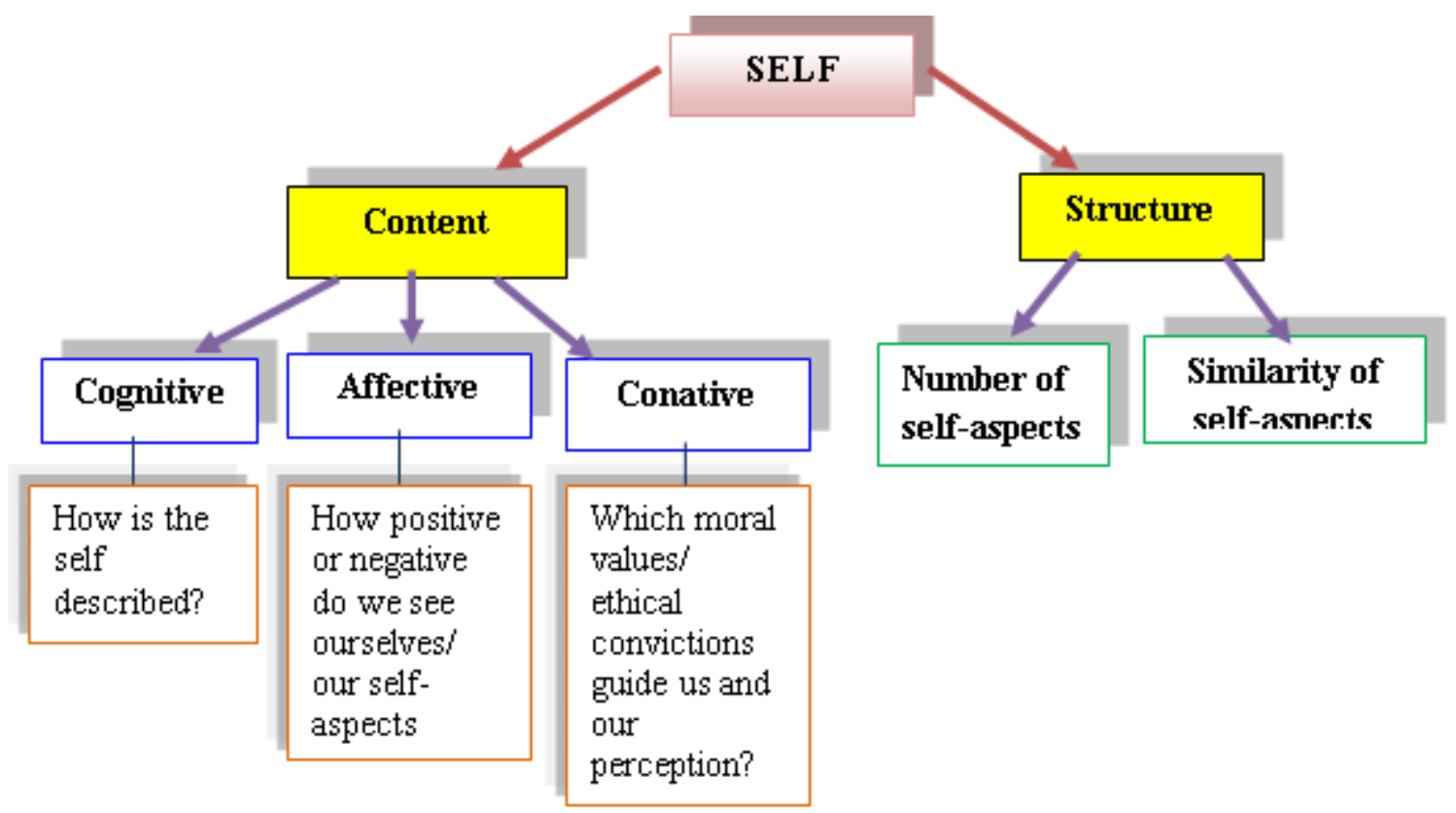

Figure 3. Dimensions of Self-Maturity (after Dorner \& Staudinger, 2003).

(Source: A Hand Book of Wisdom by Robert JS and Jennifer J,,2005)

Mature of self is based on a conceptualization of the self-concept that distinguishes between content and structure. From the figure illustrates how these two basic dimensions the self concept and the personality growth as defined self-esteem in self-complexity, integration, and value orientation. Only if we have enough self-esteem we can develop and courage and/or confidence to find out more about ourselves and world. A mature person has to be self-complex, the complexity need to be integrated by means of a common selfdescriptive core that cuts across different self-aspects. That experiences allows with consistent self across different self aspects. Here, without self-complexity, the person lack of identity or "self-sameness" (Ericson, 1959) as a vital antecedent of psychological health and maturity (Campbell, Assanand, \& DiPaula, 2003).

The conceptualization of personality growth that characterize as mature person in areas of cognition, emotion, motivation, and volition, that are: a) rich self-knowledge, refers to deep insight into one-self; b) heuristics for growth and self-regulation, refers to how to develop and maintain deep social relations; c) interrelating the self, refers to the ability to reflect on and have insight in the possible causes of one's behavior and/or feelings or linked to personal characteristics. Integrated complexity can be applied to achieve many things. A wise person is driven by self-transcending values and by attempt to balance self-centered and altruistic goals (Kunzmann \& Baltes, 2003). The emerging relational pattern was such that integration, value orientation, and self-esteem showed strong relations with social maturity and adaptation, whereas complexity and value orientation related more strongly to indicators of personal maturity or personal wisdom (Dorner \& Staudinger, 2003).

\section{G. CONCLUSION}

Human are social creatures, embedded within a culture, each of us encounters ever changing social settings that shape our actions and values, our sense of identity, our perception of reality. The sociocultural perspective examines how the social environment and cultural learning influence our behavior, thoughts, and our feelings. A wisdom culture will endured values, beliefs, behavior, and traditions that are shared by large group of people and passed from generation to the next, that will their cultural groups and develop their own social norms.

Wisdom fights to exist and has been found to maintain itself across the lifespan, neither increasing nor decreasing with age. Intelligence divided into two parts: wisdom which considered to be moral perfection, and scientia that refer to knowledge of the material world. The different conceptualization of wisdom culture between Western and Eastern found that it is of interest to know how these traditional meanings may have had an impact on the understanding of wisdom across cultures.

Aristotle considered wisdom to be one of the most basic human virtue. Birren and Fisher review that "Wisdom is the organismic integration of the affective, conative, and cognitive aspects of human abilities in response 
to life's tasks and problems. Personality is a product of interacting biological and environmental influences. Environment exists at many different levels in which we develop. In development approach, cultural wisdom is embedded of intellectual development that interacting to the function of mechanics and pragmatics of intelligence.

Life experience alone has not been found to be a predictor of wisdom related to knowledge. That was found when individuals identified as experts in life matters were assessed for their wisdom related knowledge, they performed better than their non expert counterparts also the individuals who received training and practice in domains related to conduct and meaning of life.

Cultural wisdom is related to performance by presenting individuals with fictitious life dilemmas. The abilities deal with uncertainty, inconsistency, imperfection, and compromise. The conceptualization of growth personality characterized as mature person in areas of cognition, emotion, motivation, and volition. Factors facilitative to wisdom-related knowledge have been identified, that wisdom and adult age are not directly related, however does not mean that wisdom cannot and does not increase across the lifespan. Older adults likely as their younger counterparts in wisdom-related knowledge (Staudinger,1992). Given that wisdom is related to fundamental life knowledge, a program that could potentially increase knowledge would be advantageous to both physical and emotional well-being in old age.

To help society deal with complex problems, we need people having well-developed intellects and worldly skill who have taken that extra steps and have freed themselves, to a large extent, from the tyranny of wanting or condemning mind. We really need people who are led to spend their whole lives in spiritual practice. We need those people as researchers for better ways. We need them as teachers and guides in tomorrow's cultures wisdom. We need them to show us through the examples of their lives, what life is like at the far reaches of the path to help them find meaning, to help them lay realistic plans for doing it, to help them to deal with existential crises in their lives, and to discuss a wisdom culture and the process of spiritual development in their role as life management counselors that who have led full rich lives and grown in a culture wisdom for becoming wise and making progress, and bring the wisdom culture to all their daily activities.

\section{REFERENCES}

Assmann, A (1994). Concept of wisdom in historical and cross-cultural perspective.

Adler, M, J. (1952). The Great Ideas: A syntopicon of great books of the western world. (Vol.2)). Chicago: William Benton Publisher.

Baltes, P. B. (1987). Theoretical propositions of life-span developmental psychology: On the dynamics between growth and decline. Developmental psychology. Cambridge University Press.

Baltes. P., \& Smith, J (1990). Toward a psychology of wisdom and its ontogenesis. In R.Sternberg Ed.). Wisdom: Its nature, origins and development.

Baltes, P.B., Staudinger,U.M., Maercker.A.,\&Smith,J. (1995). People nominatedas wise: A comparative study of wisdom-related knowledge. Psychology and Aging, 10, 155-166.

Bubeck, E.D, (1995). Care, gender and justice. Oxford, UK: Claredon Press.

Berrnnet, 2003, The Book of Virtues, Cambridge University Press.

Bond MH. Localizing the imperial outreach. American Behavioral Scientist. 2000;44:63-72.

Brugman, G. (2000). Wisdom: Source of narrative coherence and eudaimonia. Delft, The Nederlands: Uitgeverij Eberon.

Birren, J. E., \& Fisher, L,. M. (1990). Conceptualizing wisdom: the primacy of affect-cognition relations. . In R. Sternberg (Ed.). Wisdom: Its nature, origins and development.

Crenshaw, J. (1976). Studies in ancient Israeli wisdom. New York: Klave Publishing House. 
Cheung FM, Leung K, Zhang J, Sun H, Gan Y, Song WZ, et al. Indigenous Chinese personality constructs: Is the five factor model complete?. Journal of Cross-Cultural Psychology. 2001;32:407433.

Dorner,J. \& Staudinger, U.M. (2003). Personality growth from inside: The Mature self-concept. Unpublished manuscript. International University Bremen, Bremen, Germany.

Ericson, E.H. (1959). Identity and the life cycle. New York: International University Press.

Hashimoto, A. (1996). The gift of generations: Japanese and American perspectives on aging and the social contract. Cambridge, UK: Cambridge University Press.

James, W. (1902). Varieties of religious experience. New York: Longmans

Green.Kramer, D. A (1990). Conceptualizing wisdom: the primacy of affect-cognition relations. In R. Sternberg (Ed.). Wisdom: Its nature, origins and development.

Konstabel K, Realo A, Kallasmaa T. Exploring the sources of variations in the structure of personality traits across cultures. In: McCrae RR, Allik J, editors. The Five-Factor Model across cultures. New York: Kluwer Academic/Plenum Publishers; 2002. pp. 29-52.

Mastor KA, Jin P, Cooper M. Malay culture and personality. American Behavioral Scientist. 2000;44:95-111.

Michael W. Passer \& Ronald E. Smith (2004). Psychology: The Science of Mind And Behavior. Second Edition. The McGraw-Hill

Pasupathi, M., \& Staudinger, U.M. (2001). Do Advanced moral reasoners also show wisdom? Linking moral reasoning and wisdom-related knowledge and judgment. International Journal Behavior Development, 25(5).

Robinson, D.N. (1990) Wisdom through the ages, New York: Cambridge University Press.

Sinnot, D., J (1991). The Development of logic in adulthood: Postformal thoughts and its applications. New York: Preager.

Sternberg, R., J. (1998). A balance theory of wisdom. A Review of General Psychology, 2, 347-365. New York: Cambridge University Press.

Sendy, S. Widjaya. (2010). Business Culture in Indonesia. Jakarta: PT Endoseni Murni.

Takayama, M. (2002). The concepts of wisdom and wise people in Japan. Unpublished doctoral dissertation, Tokyo university, Japan.

Yang KS. Chinese personality and its change. In: Bond MH, editor. The psychology of the Chinese people. Oxford, UK: Oxford University Press; 1986. pp. 106-170.

\section{BIODATA}

Hernawati W Retno Wiratih is an General Subjects lecturer at the President University, Bekasi, Indonesia. Currently she is a PhD candidate at Universitas Persada Indonesia, Jakarta, Indonesia.

M. Havidz Aima is a Professor of Economic and Entrepreneurship Management at the Mercu Buana University, Jakarta Indonesia. He is also a trainer of Entrepreneurship and Leadership. 